\title{
Educação em saúde com adolescentes quilombolas como estratégia de construção da paz
}

\author{
Vanessa Cedraz dos Santos $^{1}$, Aisiane Cedraz Morais ${ }^{2}$, Sinara de Lima Souza ${ }^{3}$
}

\begin{abstract}
Resumo
O objetivo deste trabalho consiste em relatar a experiência extensionista em uma escola pública com adolescentes quilombolas tendo a educação em saúde como estratégia para construção da paz. A metodologia considerou a utilização do método participativo e o desenvolvimento de atividade lúdica entre adolescentes de 11 a 18 anos pertencentes à escola municipal da comunidade negra rural quilombola localizada na zona rural de Feira de Santana-Ba. Resultouse no desenvolvimento das atividades que favoreceram a promoção da autoestima, autoafirmação racial e o resgate à identidade do adolescente negro, contribuindo com empoderamento para enfrentar o racismo/violência e o reforço às estratégias de construção da paz. A metodologia utilizada possibilitou a aproximação dos alunos à nova forma de atividade. Compreende-se os prováveis fatores que motivam a violência entre os adolescentes e constata-se a necessidade da continuidade de ações educativas.
\end{abstract}

\section{Palavras-chave}

Violência. Vulnerabilidade em saúde. Grupo com ancestrais do continente africano. Adolescente.

\footnotetext{
${ }^{1}$ Graduanda em Enfermagem na Universidade Estadual de Feira de Santana, Bahia, Brasil; integrante do Núcleo Interdisciplinar de Estudos sobre Vulnerabilidade e Saúde (NIEVS/UEFS); bolsista PROEX/UEFS. E-mail: vanessacedraz@gmail.com.

2 Doutora em Enfermagem pela Universidade Federal da Bahia, Brasil; professora adjunta da Universidade Estadual de Feira de Santana, Bahia, Brasil; integrante do Núcleo Interdisciplinar de Estudos sobre Vulnerabilidade e Saúde (NIEVS/UEFS) e do Grupo de Estudos da Saúde da Criança e do Adolescente Crescer (EE/UFBA). E-mail: aisicedraz@hotmail.com.

${ }^{3}$ Doutora em Enfermagem pela Universidade de São Paulo, Brasil; professora titular da Universidade Estadual de Feira de Santana, Bahia, Brasil; integrante do Núcleo Interdisciplinar de Estudos sobre Vulnerabilidade e Saúde (NIEVS/UEFS). E-mail: sinarals@uefs.com.
} 


\title{
Health education with quilombola adolescents as a peace-building strategy
}

Vanessa Cedraz dos Santos ${ }^{4}$, Aisiane Cedraz Morais ${ }^{5}$, Sinara de Lima Souza ${ }^{6}$

\begin{abstract}
The objective of this work is to report the extension experience in a public school with quilombola adolescents with health education as a strategy for peace- building. The methodology considered the use of the participatory method and the development of ludic activity among adolescents aged between 11 and 18 years, belonging to a municipal school in the quilombola rural black community located in the rural area of Feira de Santana-Ba. It resulted in the development of activities that favored the promotion of self-esteem, racial selfaffirmation, the recovery of the identity of black adolescents, contributing to the empowerment to face racism/violence and the reinforcement of peace-building strategies. The methodology used made it possible for students to approach the new form of activity. We understand the probable factors that motivate violence among adolescents and we see the need for continuing educational activities.
\end{abstract}

\section{Keywords}

Violence. Health Vulnerability. African continental ancestry group. Adolescent.

\footnotetext{
${ }^{4}$ Undergraduate student in Nursing, State University of Feira de Santana, State of Bahia, Brazil; member of the Interdisciplinary Center for Studies on Vulnerability and Health (NIEVS/UEFS); PROEX/UEFS scholarship. E-mail: vanessacedraz@gmail.com.

${ }^{5} \mathrm{PhD}$ in Nursing, Federal University of Bahia, State of Bahia, Brazil; adjunct professor at the State University of Feira de Santana, State of Bahia, Brazil; member of the Interdisciplinary Nucleus for Studies on Vulnerability and Health (NIEVS/UEFS) and the Study Group on the Health of Children and Adolescents Growing (EE/UFBA). E-mail: aisicedraz@hotmail.com.

${ }^{6} \mathrm{PhD}$ in Nursing, University of São Paulo, State of São Paulo, Brazil; professor at the State University of Feira de Santana, State of Bahia, Brazil; member of the Interdisciplinary Center for Studies on Vulnerability and Health (NIEVS/UEFS). E-mail: sinarals@uefs.com.
} 


\section{Introdução}

A variável raça/cor da pele é um fator significativo no que concerne à saúde da população negra e às desigualdades sociais, sendo utilizada em estudos epidemiológicos que abrangem e apresentam elevados índices de iniquidades em saúde, nos contrastes relacionados à educação, ao trabalho, e às elevadas taxas de morbimortalidade, principalmente por causas violentas. No Brasil, as péssimas condições de saúde da população negra são retratadas como um problema de saúde pública (MALTA et al., 2017).

As ações de educação em saúde voltadas para o público adolescente, realizadas na escola, promovem resultados satisfatórios e eficientes quando as intervenções educativas são desenvolvidas numa perspectiva preventiva, proporcionando o incentivo ao reconhecimento e à condutas e princípios que favoreçam a proteção contra riscos (GONÇALVES et al., 2016) e situações de vulnerabilidade, entendendo vulnerabilidade como, de acordo com MalágonOviedo e Czeresnia (2015), todos os aspectos de adversidades relacionados ao contexto no qual o indivíduo está inserido, traduzindo-se em fatores socioeconômicos, raciais/étnicos, religiosos e de gênero.

A adolescência é o período de início da formação da identidade pessoal de cada sujeito, e compreende um desenvolvimento ininterrupto que sofre interferências externas. Essa identidade é estabelecida através de elementos relacionados à experiência cultural. Algumas comunidades quilombolas podem, ou não, expressar, pelos seus membros, traços de orgulho étnico referentes à identidade étnica (ALVES et al., 2017). É uma fase de transformações que ocorrem entre a infância e a idade adulta, ocasionando alterações de ordem psicobiológicas, físicas e sociais. A relevância desse período de transição para a área da saúde está nas repercussões que essas mudanças provocam nos comportamentos dos adolescentes, tornando-os vulneráveis, e em como esse processo pode influenciar no desenvolvimento desses indivíduos (GONÇALVES et al., 2016).

Conforme o Art. $2^{\circ}$ do Estatuto da Criança e do Adolescente, a adolescência compreende o período de 12 a 18 anos de idade. Para o Ministério da Saúde (MS) no Brasil, que segue a referência da Organização Mundial da Saúde (OMS), a adolescência corresponde a uma fase de desenvolvimento entre os 10 e 19 anos de idade (BRASIL, 2018a, 2019).

Nesse contexto da adolescência, destaca-se a vulnerabilidade de adolescentes quilombolas, partindo da compreensão de que as comunidades quilombolas, de organização social e tradicional negra, historicamente resistentes ao regime escravista, e, nos dias atuais, reivindicantes ao reconhecimento territorial e pela promoção da saúde. Com o apoio dos 
militantes do Movimento Negro, a partir da década de 1970, as necessidades da população quilombola são debatidas e enfrentadas por meio das discussões em relação às injustiças sociais, à discriminação racial, às experiências dos diversos tipos de violência e à vulnerabilidade social, econômica e psicológica (BRASIL, 2016; ALVES et al., 2017).

Entre os enfrentamentos socioambientais, o racismo e a discriminação apresentam-se como fatores significativos que repercutem na saúde das comunidades quilombolas (LACERDA; SILVA, 2016). Para Almeida (2019), o racismo é constantemente estrutural, e se configura como componente social intrínseco nos contextos político, econômico e jurídico, provocando iniquidades. Segundo Araújo (2014), todas as pessoas são vulneráveis à violência no Brasil, todavia, a população pobre e, sobretudo, negra, padece das diversas ações violentas caracterizadas como atos físicos e/ou simbólicos. O fenômeno da violência é compreendido como o uso da força, do poder e atos de dominação e submissão contra um indivíduo, grupos ou uma sociedade, provocando, ou podendo provocar, lesão, dano psicológico, deficiência ou privação de desenvolvimento, e morte. E que se apresenta de diferentes maneiras como: violência física, violência psicológica/emocional, violência sexual, negligência, violência de gênero, violência institucional, violência social, violência moral, entre outras (MOREIRA et al., 2017; BRASIL, 2018b). Destaca-se que a violência é um evento de caráter multifatorial manifestado em diversos setores da sociedade.

Os impactos que a violência pode acarretar para a vida e a saúde dos adolescentes são de ordem física, psíquica e social. Observa-se o comprometimento escolar e das relações sociais, além de desencadear distúrbios comportamentais. Adolescentes vítimas de atos violentos podem apresentar lesões físicas; comportamentos de risco para a saúde (como tabagismo, consumo de bebidas alcoólicas e de drogas ilícitas); problemas de saúde mental, tal como o distúrbio de estresse pós-traumático, transtornos de humor (especialmente a depressão), transtornos de personalidade e distúrbios de ansiedade; elevado risco de envolvimento em mais situações de violência; e interferências nas relações familiares e de amizade (SANTANA, R.; SANTANA, J., 2015; PATIAS, SILVA, DELL'AGLIO, 2016; NEV, 2015).

Conforme a Declaração de 1999 realizada pela ONU, “a paz não é apenas ausência de conflitos, mas constitui-se num processo positivo, dinâmico e participativo em que se promova o diálogo e se solucionem os conflitos dentro de um espírito de entendimento e cooperação mútuos" (REICHENBACH; FONSECA, 2016, p. 335). Em seu Art. 4º o documento refere que um dos caminhos imprescindíveis para a construção da Cultura de Paz é através da educação, em todos seus níveis (REICHENBACH; FONSECA, 2016). É a partir 
dessa premissa que julgamos necessárias e fundamentais as atividades de educação com adolescentes de uma comunidade quilombola, com princípios de raça e saúde, resgate à identidade quilombola, construção da paz, respeito ao próximo e empoderamento para possíveis situações de violência.

Este trabalho é um relato de experiência sobre a vivência como acadêmica de Enfermagem e integrante do Núcleo Interdisciplinar de Estudos sobre Vulnerabilidade e Saúde (NIEVS) em atividade extensionista em uma escola municipal de comunidade quilombola na sede do distrito de Matinha dos Pretos na cidade de Feira de Santana, Bahia, trazendo as percepções e considerações da bolsista sobre as atividades que abordavam os temas: "Meu corpo como identidade biológica, cultural e racial", "Violência e saúde", "Enfrentamento da violência e as consequências da violência na saúde", realizadas com adolescentes do $6^{\circ}$ ao $9^{\circ}$ ano do ensino fundamental do turno matutino. O plano de trabalho das ações foi desenvolvido propondo atividades pautadas na educação em saúde e na divulgação de estratégias de construção da paz entre adolescentes de uma comunidade quilombola, com finalidade de combater a violência na escola e fora dela, assim como resgatar a identidade e autonomia do adolescente negro, favorecendo o seu empoderamento para enfrentar o racismo/violência, resgatando, inclusive, questões inerentes à saúde da população negra.

Nessa perspectiva, considerando a importância do processo educativo em saúde, que visa a compreensão do processo saúde-doença e a promoção da saúde, a interlocução do conhecimento científico e do popular, favorece o reconhecimento das vulnerabilidades e a valorização dos saberes do público adolescente, além da construção do conhecimento por meio da educação popular, propiciando a reflexão crítica diante dos contextos vivenciados por eles.

As atividades extensionistas foram norteadas pelos princípios da indissociabilidade entre ensino/extensão voltadas à sociedade, proporcionando articulação entre a academia e comunidade, reforçando o compromisso social da Universidade e, especialmente através dessa proposta de trabalho, um retorno para uma população que foi historicamente excluída e negligenciada.

Diante das diversas formas de violência enfrentadas no cotidiano dos adolescentes, sobretudo sob o viés racial, perpetradas em vários ambientes e por diferentes atores da sociedade, e os impactos na saúde, observou-se a necessidade de compreender suas percepções acerca da violência em suas diversas nuances e promover a reflexão sobre o enfrentamento desse fenômeno. Assim, a bolsista e orientadoras integrantes do NIEVS, 
núcleo que possui articulação com outras escolas do município e outros projetos relacionados à violência na escola e à violência contra a mulher, estabeleceu a abordagem da temática dando continuidade no desenvolvimento das atividades na escola, iniciadas em 2017.

Este trabalho tem como objetivo relatar a experiência extensionista em uma escola pública com adolescentes quilombolas tendo a educação em saúde como estratégia para construção da paz.

\section{Metodologia}

As atividades se iniciaram com a realização de pesquisas para a aquisição de referencial teórico para fundamentar as atividades, seguido de reuniões para a apresentação do trabalho de extensão com a presença de representantes docentes e representantes discentes da escola escolhida, para que juntos, e mobilizados, pudéssemos avaliar as propostas e criar estratégias para a implantação, bem como inserir propostas sugeridas pela comunidade local.

As ações educativas foram realizadas com grupos de adolescentes entre 11 a 18 anos, pertencentes à Escola Municipal Rosa Maria Esperidião Leite, localizada na Avenida Anízio Pereira, s/n, na Comunidade Negra Rural Quilombola no distrito de Matinha dos Pretos, localizada na zona rural de Feira de Santana, Bahia. Com carga horária definida (máximo de 2 horas), os encontros foram marcados de acordo com a disponibilidade de horário da escola. Durante a realização dos encontros com os adolescentes buscamos a promoção do pensamento crítico, a participação e a dinamicidade nas atividades elaboradas, por meio de oficinas temáticas, dinâmicas, atividades em grupo, rodas de conversa, confecção de cartazes, entre outros, onde temas como: "Meu corpo como identidade biológica, cultural e racial"; "Violência e saúde"; "Enfrentamento da violência e as consequências da violência na saúde".

Utilizando uma metodologia participativa e o desenvolvimento de atividade lúdica onde os próprios adolescentes desenvolveram painéis com imagens e frases, e, em seguida, apresentavam suas produções e explicavam os significados dos detalhes dos painéis abordando os referidos temas propostos.

Além dessas atividades, foi possível ainda analisar a situação da saúde (física e psicológica) desses adolescentes e fazer os encaminhamentos necessários; sistematização e socialização de experiências vivenciadas com os membros do núcleo de pesquisa no qual a bolsista e a orientadora estão vinculadas. 


\section{Resultados e Discussão}

Por meio das atividades desenvolvidas, possibilitamos momentos de discussões sobre os temas: "Meu corpo como identidade biológica, cultural e racial"; "Violência e saúde"; "Enfrentamento da violência e as consequências da violência na saúde", com a finalidade de promover a autoestima, autoafirmação racial, o resgate da identidade do adolescente negro e respeito ao próximo, favorecendo o seu empoderamento para enfrentar o racismo/violência e o reforço às estratégias de construção da paz, importantes para o enfrentamento da violência em diversos contextos. As atividades foram coerentes com a ideia de Martins de Oliveira et al. (2016), que ressaltam a importância das ações voltadas ao adolescente, contribuindo para o desenvolvimento do indivíduo tanto no âmbito social, como familiar.

A ação extensionista é a continuidade no desenvolvimento das atividades na comunidade Matinha dos Pretos, que iniciou com uma reunião com a presença de professores e pais (41 pessoas) na qual foi apresentado o relatório final do projeto relativo a 2017-2018 (Estratégias de construção da paz numa Escola Municipal de Comunidade Quilombola, realizado na referida escola onde 508 alunos participaram das atividades) e a apresentação do projeto atual referente a 2018-2019 (Raça e Saúde: Educação com Adolescentes Quilombolas como Estratégias de construção da paz).

As atividades ocorreram entre os meses de novembro de 2018 e abril de 2019. Foram iniciadas com a realização de oficinas com o tema: "Meu corpo como identidade biológica, cultural e racial", com a participação de 117 estudantes distribuídos em 5 turmas do turno matutino, eles desenvolveram painéis com imagens e frases usando jornais e revistas abordando o referido tema. A metodologia utilizada nas oficinas possibilitou a aproximação dos estudantes à nova forma de atividade com a utilização de revistas e jornais, favorecendo o incentivo à produção criativa. Em seguida os estudantes apresentavam suas produções e explicavam os significados dos detalhes dos painéis em que representavam como identidade da população negra, surgindo assim os termos: aceitação, respeito à diversidade, oportunidades para a população negra, capoeira, uso de turbantes, luta pela liberdade, beleza da mulher negra, cabelos crespos, condições sociais da população negra, entre outros. Tal atividade objetivou promover a autoestima e autoafirmação racial dos adolescentes. A barreira encontrada no desenvolvimento dessa atividade foi a dificuldade na concentração e organização dos adolescentes durante as produções dos painéis. 
Foram realizadas as discussões com os temas: "Violência e saúde" e "Enfrentamento da violência e as consequências da violência na saúde", favorecendo o reforço das estratégias de construção da paz entre os adolescentes quilombolas.

No que concerne ao tema "Violência e saúde", os adolescentes criaram painéis a partir das respostas aos questionamentos que foram: o que eu sinto quando...? (foram apresentados exemplos de violências e o que eles sentem quando veem, por exemplo, crianças sendo machucadas, mulheres sendo agredidas, atos de racismo e bullying, brigas entre adolescentes, entre outros). Alguns se mostraram indignados com os exemplos expostos, e, assim, gradativamente iam escrevendo nos painéis suas opiniões. As respostas foram: raiva, medo, pena, indignação, revolta, incapacidade, vontade de bater no agressor, aflição, repulsa, entre outros, em seguida, as respostas eram lidas e discutidas. Participaram dessa atividade 167 estudantes de 7 turmas. O empecilho na realização dessa atividade foi a dispersão de alguns adolescentes.

Para o tema enfrentamento da violência, as questões foram: o que eu faço quando...? (Foram utilizados os mesmos exemplos de violências do tema anterior), o que a sociedade faz...? E porque as pessoas não estão enfrentando as violências...? As respostas referentes aos questionamentos sobre o que eles fariam em relação aos atos de violências citados foram: denunciaria o/a agressor/a, ajudaria a pessoa agredida, denunciaria para a polícia e/ou para o Conselho Tutelar, avisaria ao familiar, entre outros.

Sobre o que a sociedade faz em relação aos atos violentos, eles responderam que na maioria das vezes, diante de circunstâncias violentas, a população é omissa devido ao comodismo ou medo; em outras situações, lincham os agressores; entram em pânico; outros, realizam denúncia para a polícia e/ou Conselho Tutelar; a sociedade cria leis; aumento de penas para os agressores, além de campanhas educativas, entre outros.

Os discentes foram questionados sobre quais são as consequências da violência na saúde dos adolescentes, eles citaram que os adolescentes afetados podem apresentar tristeza, depressão, automutilação, desinteresse pelos estudos, pensamentos suicidas e suicídio. Nessa atividade, realizada com a participação de 146 estudantes de 6 turmas, os adolescentes verbalizaram suas opiniões e/ou as escreveram em papéis para posterior leitura durante a discussão. Assim como na atividade anterior, alguns ficaram dispersos e não interagiram com a atividade, comprometendo a participação dos demais. Durante as atividades, alguns adolescentes relataram experiências vivenciadas nos ambientes de convívio, como por exemplo, a agressão física sofrida por um familiar de uma adolescente, pelo cônjuge, com o uso de arma branca. Salienta-se a relevância da abordagem e discussão das temáticas no 
processo educativo desenvolvido nessas atividades, pois corroborou para exposição dos pensamentos e opiniões dos adolescentes. Para Alberti et al. (2014, p. 78),

A educação problematizadora insere a realidade dos sujeitos no contexto educativo mediante a valorização do diálogo, da reflexão e da criatividade de modo a construir a libertação. É nessa perspectiva teórica que se insere a adolescência, as vulnerabilidades e as potencialidades dessa etapa em que se produzem conhecimentos e saberes, e a realidade individual de cada sujeito como objeto de reflexão.

A interação da escola com a bolsista e orientadora favoreceu a continuidade de atividades e a execução do novo projeto (2018-2019). Foi enfatizada pela diretoria a importância da realização da apresentação do relatório final do projeto (2017-2018), haja vista que ele apresentou para os docentes e diretoria os principais tipos de violência identificados e os fatores de risco para a ocorrência de violências na escola. Durante a reunião, os docentes participaram com sugestões de temas e ações segundo as demandas vivenciadas por eles.

E, novamente, vale destacar a acessibilidade da escola para o desenvolvimento das atividades propostas, favorecendo a adequação e flexibilidade das turmas na organização de salas; bem como pela disponibilidade de materiais para a execução das oficinas e a participação de docentes na sala de aula durante as atividades. Com a finalização das atividades, foram atendidos o total de 430 adolescentes, distribuídos em 7 turmas do turno matutino.

Além das atividades internas na escola, como meio de divulgar as ações de cultura da paz em toda comunidade quilombola, foi realizada, em dezembro de 2018, uma "Caminhada pela Paz" no local, com a participação expressiva dos discentes, docentes, diretoria e funcionários e também pais e funcionários da Escola Municipal infantil do distrito de Matinha dos Pretos, reforçando a importância do enfrentamento à violência pelos adolescentes e pela comunidade.

A realização da "Caminhada pela Paz" teve boa repercussão na comunidade, sendo elogiada pelos moradores e foi significativa para reflexão sobre o enfrentamento da violência pela sociedade; além do fortalecimento da ideia com a presença de participantes da campanha Feira Pede Paz (campanha da Prefeitura local) e o incentivo para outras escolas participarem de discussões sobre violência e a construção da paz.

Nesse sentido, destaca-se que a cidadania e cultura de paz são aspectos inerentes, não apenas à constituição e ao direito à saúde e à educação, mas, além disso, são fatores 
fundamentais para a implementação de qualquer ação que inclua sujeitos em prol de melhorias, qualidade de vida e bem-estar (CORRÊA et al., 2015).

O evento da "Caminhada para a Paz" foi encerrado com apresentação do coral dos adolescentes da Escola Rosa Maria Esperidião Leite, que lhes propiciou a motivação em relação a atividades culturais como música, dança e teatro, além da motivação para os professores discutirem a temática de violência e raça. Favoreceu o incentivo às atividades culturais percebidas como umas das maneiras de enfrentamento da violência no âmbito escolar e social.

\section{Considerações finais}

A realização dessa ação educativa propiciou a escuta dos relatos dos adolescentes tendo em vista a compreensão de suas vulnerabilidades e percepções sobre a temática, vinculada à sua história quilombola e de sua fase de vida, que engloba um período de descobertas e dúvidas, bem como de formação da identidade, ou seja, levou-se em conta os possíveis fatores, internos e externos, ao contexto escolar, que podem influenciar em atitudes violentas pelos adolescentes e suas repercussões.

Nesse sentido, destacamos a importância de abordar o tema raça e saúde e o reforço das estratégias de construção da paz entre adolescentes de uma comunidade quilombola, visando à promoção da autoestima e autoafirmação racial dos adolescentes, o enfrentamento da violência e a discussão sobre a interferência dos diversos tipos de violências na saúde dos adolescentes e na sociedade. Constata-se a necessidade da continuidade de ações educativas.

As limitações para o desenvolvimento das atividades foram a dificuldade na concentração e organização dos adolescentes durante as produções dos painéis e, com a deflagração da greve nas escolas municipais e nas universidades estaduais da Bahia, ocorreu interrupção das atividades; entretanto, elas foram retomadas ao término da greve.

Para a comunidade universitária, as atividades contribuíram para articulação da academia versus comunidade, bem como foi perceptível a existência de outras demandas dos adolescentes e do distrito para além da execução dos temas propostos, para as quais docente e bolsista atenderam, fortalecendo o vínculo entre a comunidade local e a universidade.

\section{Referências}

ALBERTI, G. F. et al. Educação popular trabalhada em oficinas de saúde: a sexualidade durante o adolescer. Rev. Ed. Popular, Uberlândia, v. 13, n. 1, p. 75-81, jan./jun. 2014. 
Doi: 10.14393/REP-v13n12014-art06. Disponível em:

http://www.seer.ufu.br/index.php/reveducpop/article/view/24871/14615. Acesso em: 7 abr. 2021.

ALMEIDA, S. L.de. Racismo estrutural. São Paulo: Sueli Carneiro; Pólen, 2019.

ALVES, T. de A. et al. Identidade étnica: percepção de adolescentes quilombolas. Unimontes Científica, Montes Claros, v. 19, n. 1, jan./jun. 2017. Disponível em:

https://www.periodicos.unimontes.br/index.php/unicientifica/article/view/2054. Acesso em: 25 mar. 2021.

ARAÚJO, J. de A. Racismo, violência e direitos humanos: pontos para o debate. Revista Interdisciplinar de Direitos Humanos, Bauru, v. 2, n. 2, p. 75-96, jun. 2014. Disponível em: https://www3.faac.unesp.br/ridh/index.php/ridh/article/view/177. Acesso em: 25 mar. 2021.

BRASIL. Estatuto da Criança e do Adolescente. Lei n. 8.069, de 13 de julho de 1990. Brasília, 2019. Disponível em: https://www.mdh.gov.br/todas-as-noticias/2019/maio/governofederal-lanca-nova-edicao-do-estatuto-da-crianca-e-do-adolescente-eca/ECA2019digital.pdf. Acesso em: 25 mar. 2021.

BRASIL. Ministério da Saúde. Secretaria de Gestão Estratégica e Participativa. Departamento de Articulação Interfederativa. Temático Saúde da População Negra. Brasília: Ministério da Saúde, 2016. Disponível em:

http://bvsms.saude.gov.br/bvs/publicacoes/tematico_saude_populacao_negra_v._7.pdf. Acesso em: 25 mar. 2021.

BRASIL. Ministério da Saúde. Secretaria de Atenção à Saúde. Departamento de Ações Programáticas e Estratégicas. Proteger e cuidar da saúde de adolescentes na atenção básica. 2. ed. Brasília: Ministério da Saúde, 2018a. Disponível em:

http://bvsms.saude.gov.br/bvs/publicacoes/proteger_cuidar_adolescentes_atencao_basica_2ed .pdf. Acesso em: 25 mar. 2021.

BRASIL. Ministério dos Direitos Humanos. Secretaria Nacional de Proteção dos Direitos da Criança e Adolescente. Violência contra crianças e adolescentes: análise de cenários e propostas de políticas públicas. Brasília: Ministério dos Direitos Humanos, 2018b. Disponível em: https://www.mdh.gov.br/biblioteca/consultorias/conada/violencia-contra-criancas-eadolescentes-analise-de-cenarios-e-propostas-de-politicas-publicas.pdf. Acesso em: 25 mar. 2021.

CORRÊA, P. M. et al. Vivências em promoção da saúde: articulando saberes com estudantes de escolas públicas. Extensio, Florianópolis, v. 12, n. 19, p. 14-24, set. 2015. Doi:

10.5007/1807-0221.2015v12n19p14. Disponível em:

https://periodicos.ufsc.br/index.php/extensio/article/view/1807-0221.2015v12n19p14. Acesso em: 10 mar. 2021.

GONÇALVES, L. F. F. et al. Promoção de saúde com adolescentes em ambiente escolar: relato de experiência. Sanare, Sobral, v. 15, n. 2, p. 160-167, jun./dez. 2016. Disponível em: https://sanare.emnuvens.com.br/sanare/article/view/1051. Acesso em: 25 mar. 2021. 
LACERDA, R. dos S.; SILVA, G. M. da. Reterritorialização, conflitos ambientais e saúde em comunidades quilombolas de Sergipe. Revista da Associação Brasileira de

Pesquisadores/as Negros/as, v. 8, n. 18, p. 239-254, nov. 2015-fev. 2016. Disponível em: https://www.academia.edu/23238221/reterritorializa\%c3\%87\%c3\%83o_conflitos_ambientais _e_sa\%c3\%9ade_em_comunidades_quilombolas_de_sergipe. Acesso em: 25 mar. 2021.

MALÁGON- OVIEDO, R. A., CZERESNIA D. O conceito de vulnerabilidade e seu caráter biossocial. Interface, Botucatu, v. 19, n. 53, p. 237-249, abr./jun. 2015. Doi: 10.1590/180757622014.0436. Disponível em: https://www.scielo.br/pdf/icse/v19n53/1807-5762-icse-1807576220140436.pdf. Acesso em: 19 maio 2021.

MALTA, D. C. et al. Fatores de risco e proteção de doenças e agravos não transmissíveis em adolescentes segundo raça/cor: Pesquisa Nacional de Saúde do Escolar. Revista Brasileira de Epidemiologia, São Paulo, v. 20, n. 2, p. 247-259, 2017. Doi: 10.1590/1980-

5497201700020006. Disponível em:

https://www.scielo.br/j/rbepid/a/TTCxh4NvTJwTx3jH5xJmbvt/?lang=pt. Acesso em: 25 mar. 2021.

OLIVEIRA, A. K. M. de et al. Ações educativas em saúde voltadas ao adolescente: um relato de experiência. Extensio, Florianópolis, v. 13, n. 23, p. 135-141, set. 2016. Doi:

10.5007/1807 - 0221.2016v13n23p135.. Disponível em:

https://periodicos.ufsc.br/index.php/extensio/article/view/1807-0221.2016v13n23p135/32687.

Acesso em: 10 mar. 2021.

MOREIRA, K. F. A. et al. Perfil das crianças e adolescentes vítimas de violência. Rev enferm UFPE [on-line], Recife, v. 11, n. 11, p. 4410-4417, nov. 2017. Doi:

10.5205/reuol.23542-49901-1-ED.1111201718. Disponível em:

https://pesquisa.bvsalud.org/portal/resource/pt/biblio-1031930. Acesso em: 25 mar. 2021.

NEV. Núcleo de Estudos da Violência. Prevenindo a violência juvenil: um panorama das evidências, 2015. Disponível em:

https://apps.who.int/iris/bitstream/handle/10665/181008/9789241509251-por.pdf. Acesso em: 25 mar. 2021.

PATIAS, N. D.; SILVA, D. G. da; DELL'AGLIO, D. D. Exposição de adolescentes à violência em diferentes contextos: relações com a saúde mental. Temas em Psicologia, Ribeirão Preto, v. 24, n. 1, p. 205-218, 2016. Doi: 10.9788/TP2016.1-14. Disponível em: http://pepsic.bvsalud.org/scielo.php?script=sci_arttext\&pid=S1413-389X2016000100010. Acesso em: 25 mar. 2021.

SANTANA, R. P. de; SANTANA, J. S. da S. Marcas e prejuízos da violência contra crianças e adolescentes segundo profissionais de hospitais públicos. Rev enferm UFPE [on-line], Recife, v. 9, supl. 1, p. 431-439, 2015. Doi: 10.5205/reuol.5221-43270-1-

RV.0901supl201523. Disponível em:

https://periodicos.ufpe.br/revistas/revistaenfermagem/article/viewFile/10356/11077. Acesso em: 25 mar. 2021.

REICHENBACH, J. P.; FONSECA, D. G. A cultura de paz na percepção dos professores de educação física de uma escola da rede estadual de ensino do Rio Grande do Sul.

Motrivivência, Florianópolis, v. 28, n. 48, p. 331-346, set. 2016. Doi: 10.5007/2175- 
8042.2016v28n48p331. Disponível em:

https://periodicos.ufsc.br/index.php/motrivivencia/article/view/2175-8042.2016v28n48p331.

Acesso em: 25 mar. 2021.

Submetido em 7 de abril de 2021

Aprovado em 6 de junho de 2021. 